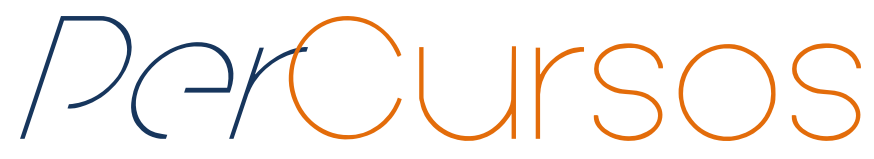

\title{
Ensino de português e o contínuo fala-escrita: o caso das estratégias de relativização
}

\section{Resumo}

O presente artigo pretende contribuir com a área do ensino de Português ao apresentar e discutir o comportamento das chamadas estratégias de relativização em função das modalidades expressivas, fala e escrita. Para tanto, trata, primeiramente, dos objetivos do ensino de Língua Portuguesa e das concepções de normas que fundamentam as reflexões feitas. Em seguida, com base em três estudos sociolinguísticos (PEREIRA, 2014; FERREIRA, 2013; SANTOS, 2015), sistematiza o uso das estratégias de relativização no contínuo fala-escrita. Por fim, a partir da análise dos resultados, apresenta reflexões sobre o tratamento das normas linguísticas e dos fenômenos variáveis na Educação Básica.

Palavras-chave: Ensino. Variação. Estratégias de Relativização. Língua Portuguesa - Estudo e Ensino.

\author{
Silvia Rodrigues Vieira \\ Doutora em Letras Vernáculas \\ (Língua Portuguesa) pela \\ Universidade Federal do Rio de \\ Janeiro - UFRJ. Professora da \\ Universidade Federal do Rio de \\ Janeiro - UFRJ \\ Brasil \\ silviavieira@hotmail.com
}

\section{Para citar este artigo: \\ VIEIRA, Silvia Rodrigues. Ensino de português e o contínuo fala-escrita: o caso das estratégias de relativização. Revista PerCursos, Florianópolis, v. 18, n.37, p. 08 - 35, maio/ago. 2017.}

\section{DOI: $\mathbf{1 0 . 5 9 6 5 / 1 9 8 4 7 2 4 6 1 8 3 7 2 0 1 7 0 0 8}$}

http://dx.doi.org/10.5965/1984724618372017008 


\title{
Portuguese teaching and the speech-writing continuum: the case of relativization strategies
}

\begin{abstract}
This article aims at contributing to the Portuguese teaching area by presenting and discussing the behavior of so-called relativization strategies, taking into consideration speech and writing expressions. To do so, it deals first with the purposes of Portuguese language teaching and the conceptions of norms that underlie pedagogical assumptions. Afterwards, based on three sociolinguistic studies (PEREIRA, 2014; FERREIRA, 2013; SANTOS, 2015), the uses of relativization strategies are systemathised, according to the continuous from speech to writing. Finally, the analysis of scientific results provides reflections on the treatment of language norms and variable rules in Basic Education.
\end{abstract}

Keywords: Teaching. Variation. Relativization Strategies. Portuguese Language - Study and Teaching. 


\section{Introdução}

Considerando as orientações oficiais para o ensino de Português nos níveis fundamental e médio, parece já consagrada a proposta de que é preciso contemplar as estruturas típicas da chamada variedade culta, sobretudo na modalidade escrita, o que não deve implicar desprezo às variantes dominadas pelos alunos, mas antes a ampliação de seu repertório linguístico para as mais variadas situações sociocomunicativas. Embora em nada essa proposta contrarie os pressupostos gerais das pesquisas em Linguística, e mais especificamente em Sociolinguística, restam sem desenvolvimento, em boa parte dos materiais didáticos, atividades que efetivamente permitam abordar 0 comportamento dos variados fenômenos morfossintáticos em diversificados gêneros textuais orais e escritos.

Face à necessidade de que se disponibilizem sistematizações de resultados científicos que fundamentem as reflexões para o contexto pedagógico, este artigo pretende contribuir com a área do ensino de Português ao apresentar e discutir o comportamento das chamadas estratégias de relativização em função das modalidades expressivas, fala e escrita. Trata-se das chamadas orações subordinadas adjetivas, considerando suas formas de apresentação: (i) com o pronome relativo usado de acordo com a regência padrão da oração encaixada, como em o livro de que eu preciso (relativa padrão), (ii) com a ausência das preposições no contexto anterior ao pronome relativo, como em o livro que eu preciso (relativa cortadora), e (iii) com a presença do referente retomado dentro da oração adjetiva, como em o livro que eu preciso dele (relativa copiadora).

Sem dúvida, as referidas estratégias não recebem a mesma acolhida no contexto escolar, sobretudo no trabalho com a modalidade escrita. Desse modo, é preciso conhecer qual a produtividade de cada uma em contextos particulares do contínuo falaescrita, a fim de postular, com base nesse conhecimento, as diretrizes que a escola pode adotar para trabalhar as estruturas em questão. Nesse sentido, propõe-se, neste artigo, que a variação linguística no âmbito das estratégias de relativização pode ocupar a cena escolar, sem que isso signifique negar ao aluno a identificação do valor social da 
linguagem a partir das opções preferenciais verificadas nos usos. Em outras palavras, trabalhar a norma-padrão, vista como o conjunto de regras propostas como modelares para determinados ambientes comunicativos, não implica incorporar uma concepção de língua homogênea; antes, entende-se, em consonância com a proposta de Faraco (2015) para uma "pedagogia da variação linguística”, que os próprios guias normativos possam refletir a norma praticada e, nesse sentido, admitir a pluralidade.

A fim de cumprir os propósitos ora enunciados, o presente artigo organiza-se da seguinte forma: (i) primeiramente, trata dos objetivos do ensino de Língua Portuguesa (Seção 2), tomando por base a proposta do "ensino de gramática em três eixos" (VIEIRA, 2014, 2017) e as concepções de normas que fundamentam as reflexões feitas, adotando a categorização proposta por FARACO (2008); (ii) em seguida (seção 3), com base em três estudos variacionistas (PEREIRA, 2014; FERREIRA, 2013; SANTOS, 2015) ${ }^{1}$, sistematiza o uso das estratégias de relativização em entrevistas sociolinguísticas realizadas no Rio de Janeiro; em escrita de alunos no fim do ensino médio; e, ainda, em textos jornalísticos; (iii) por fim, antes das considerações finais (Seção 5), apresenta reflexões sobre o tratamento das normas linguísticas na Educação Básica (Seção 4).

\section{O ensino de Língua Portuguesa, gramática e variação}

Antes de nos atermos especificamente ao tratamento pedagógico da variação no que se refere ao contínuo fala-escrita, tratemos brevemente dos propósitos educacionais em Língua Portuguesa. Há muito, os especialistas e professores buscam um tratamento pedagógico para o componente linguístico que seja produtivo e atenda, ao menos, três necessidades: (i) promover o conhecimento teórico-descritivo sobre os recursos gramaticais; (ii) relacionar esses recursos ao vasto campo da produção de sentidos; e (iii) contemplar as expressões variáveis dos expedientes gramaticais.

\footnotetext{
${ }^{1}$ Talita da Silva Pereira e Vitor A. Ferreira, orientados por Silvia Rodrigues Vieira, desenvolveram os estudos das estratégias de relativização como atividades do Programa de Iniciação Científica da UFRJ; Juliana da Costa Santos procedeu à investigação do tema, sob a mesma orientação, em sua dissertação de Mestrado.
} 
Foi pensando nessas necessidades que Vieira $(2014,2017)$ - com base nas reflexões instauradas no âmbito da disciplina Gramática, variação e ensino, do Mestrado Profissional em Língua Portuguesa (PROFLETRAS) - propôs uma abordagem do componente linguístico em três frentes de trabalho: (i) a abordagem reflexiva da gramática; (ii) o tratamento dos expedientes gramaticais como recursos expressivos para a construção de sentido dos textos; e (iii) a análise da pluralidade de normas linguísticas, que se configuram em regras variáveis.

De modo geral, a autora, sem deixar de fazer coro à ideia de que o objetivo maior do ensino de Língua Portuguesa seja o desenvolvimento da competência de leitura e produção de textos, afirma que a abordagem do componente gramatical não pode abdicar de sua especificidade e contribuição para a formação do aluno, seja no plano da sistematização do conhecimento, seja no plano da utilização dos recursos linguísticos. Ultrapassa-se, assim, uma visão puramente instrumental do espaço da gramática em sala de aula, espaço que deve incorporar não só a reflexão sobre as categorias relevantes ao conhecimento da língua, mas também o domínio dos recursos em variadas situações interacionais. Este domínio requer a utilização de um conjunto de informações de ordem sociolinguística, quanto à configuração de regras variáveis, para o desenvolvimento de um trabalho consistente e produtivo.

Nesse sentido, não resta dúvida de que o que se convencionou chamar "ensino de gramática" se alia, embora não se equipare, com o ensino de norma-padrão, concebida como um conjunto de regras linguísticas a serem seguidas para o domínio de estruturas consideradas de prestígio em meios escolarizados, sobretudo em situações formais orais e escritas. É nesse terceiro eixo do ensino que se concentra a proposta do presente artigo: a partir do conhecimento de resultados científicos acerca de uma regra variável, referente às estratégias de relativização no Português do Brasil em expressões falada e escrita, refletir sobre o ensino de gramática, visto o componente linguístico como uma instância de manifestação de regras variáveis.

As orientações oficiais para a área de Língua Portuguesa na Educação Básica, codificadas em parte nos Parâmetros curriculares nacionais (PCN), propõem que é preciso ampliar o domínio das expressões linguísticas, de modo que o aluno possa 
“expressar-se apropriadamente" em situações diversas. O documento é afirmativo na defesa de que, em uma sociedade socialmente complexa como a brasileira, "o que se identifica é um intenso fenômeno de mescla lingüística, isto é, em um mesmo espaço social convivem mescladas diferentes variedades lingüísticas, geralmente associadas a diferentes valores sociais" (BRASIL, 1998, p. 29). É nesse contexto que se valoriza a divulgação dos padrões de uso da escrita e do que se convencionou chamar língua padrão como “objetos privilegiados de ensino-aprendizagem na escola” (p. 30).

Dada a polissemia do termo norma, cabe esclarecer que, no presente artigo, a expressão "norma-padrão" diz respeito ao conjunto de regras socialmente idealizadas como prestigiosas, seja para a modalidade falada, seja para a escrita. Embora por vezes esse conjunto possa se aproximar do que propõe a "norma gramatical”, aquela postulada em compêndios tradicionais (gramáticas e dicionários), essas instâncias não são efetivamente compatíveis ou idênticas. Reserva-se, aqui, a expressão "norma culta” para a efetiva variedade praticada por pessoas altamente escolarizadas, a partir do que se pressupõe ser mais produtivo em comunidades urbanas, sobretudo em situação mais formal ${ }^{2}$.

No contexto escolar, é absolutamente desafiador lidar com essa pluralidade de normas, sobretudo considerando o propósito de promover o contato do aluno com as mais variadas experiências de letramento, com base em gêneros das modalidades oral e escrita. De um lado, é preciso valorizar as variantes dominadas pelos alunos, em suas diversas comunidades de fala, de forma a não consolidar o preconceito linguístico; de outro, é absolutamente necessário fomentar reflexões sobre as estruturas que não pertencem à variedade que esses alunos dominam. Sem dúvida, não são poucas as construções gramaticais presentes nos materiais escolares, principalmente na modalidade escrita, que podem ser até ininteligíveis para os estudantes. Estruturas morfossintáticas típicas de situação de alta monitoração estilística, como, por exemplo, orações relativas do tipo padrão (o livro de que preciso, o livro de cuja capa lhe falei), figuram entre as construções pouco familiares à boa parte das comunidades de fala representadas pelos alunos da Educação Básica, principalmente no nível fundamental.

\footnotetext{
${ }^{2}$ A respeito da polissemia do termo norma, recomenda-se a leitura de Faraco (2008).
} 
Não obstante a distância existente entre determinadas formas cultas, sobretudo da modalidade escrita, e os usos praticados por diversos indivíduos não escolarizados ou até escolarizados ${ }^{3}$, é fato que os falantes, de forma consciente ou inconsciente, avaliam constantemente as variantes linguísticas, elegendo aquelas que caberiam nas normas por eles idealizadas como prestigiosas ou "corretas", ao menos para determinado contexto e modalidade. Desse modo, o conceito de norma-padrão acaba por constituir um postulado sociolinguístico inegável e muito atuante nas diversas sociedades contemporâneas.

Como a escola pode se comportar frente a essa complexa e plural realidade de normas linguísticas? Primeiramente, é de fundamental importância conhecer as estruturas que pertencem às normas/variedades efetivamente praticadas por indivíduos escolarizados, chamadas aqui cultas, na fala e na escrita brasileiras ${ }^{4}$. Em segundo lugar, é preciso avaliar a distância dessas normas em relação: (i) a outras normas já dominadas pelos estudantes quando chegam à escola; (ii) a outras normas que se apresentam nos diversos gêneros textuais trabalhados nas aulas de Português; e (iii) ao conjunto de regras idealizado pela tradição gramatical como padrão literário (e tantas vezes reproduzido como única possibilidade nos materiais didáticos).

É nesse sentido que figura como mais do que necessária a proposta de Faraco (2015), consoante a qual os manuais de orientação normativa precisam assumir uma concepção de norma que acomode a pluralidade, para o bem de uma pedagogia da variação linguística. O ensino pode e deve estar fundamentado em padrões reais, praticados nas normas de uso, para que as orientações oferecidas aos alunos nas práticas de escrita em diversos gêneros, segundo qualquer que seja o padrão de prestígio social adotado (e ele existe!), não sejam obsoletas e contraproducentes. Assim, traços linguísticos, produtivos em sincronias passadas e, ainda hoje, em certas tradições discursivas (como a literária, a jurídica, a religiosa, dentre outras), seriam trabalhados do

\footnotetext{
${ }^{3}$ Estudos sociolinguísticos têm demonstrado que as diferenças entre a fala culta e a popular, ao contrário do que se pensava, são mais de ordem qualitativa e de avaliação subjetiva, do que de natureza quantitativa. São poucos os fenômenos que admitem diferenças expressivas entre as variedades, embora esses fenômenos sejam suficientes, como traços descontínuos, para delimitar esses grupos de falantes.

${ }^{4}$ Vieira; Freire (2014) delinearam, a partir de resultados relativos a fenômenos morfossintáticos variáveis, estruturas prototípicas da fala, sobretudo a culta, versus um quadro bastante diferenciado das construções que se encontram em textos escritos, com graus de formalidade diversos e com maior ou menor compromisso com o que seria prototipicamente esperado como padrão.
} 
ponto de vista da recepção (e não da produção escolar), para que o aluno possa, ao menos, compreender/interpretar as estruturas em questão.

O trabalho com o componente linguístico no eixo da variação (Eixo 3, da proposta de VIEIRA, 2014, 2017) é fundamental para a operacionalização de qualquer trabalho com a gramática. A prática de leitura e produção textuais pode ficar impedida ou ao menos dificultada pela falta de domínio de certas construções linguísticas. Assim, o trabalho com a variação linguística, aliado à abordagem reflexiva da gramática, constitui condição, na maioria dos casos, para a promoção do letramento, seja no nível da recepção (leitura), seja no da criação (produção textual).

Desse modo, o acesso às chamadas variedades de prestígio na sociedade passa a ser promovido pela escola sem desconsiderar os contínuos de variação ${ }^{5}$ que configuram a pluralidade de normas de uso. Dentre esses contínuos, o presente texto destaca a relevância do que se refere à aparente dicotomia fala e escrita, intitulado contínuo de oralidade-letramento por Bortoni-Ricardo (2005) ou contínuo da relação fala-escrita por Marcuschi (2008). Essas propostas têm em comum o pressuposto de que as variantes linguísticas se distribuem de forma escalar consoante seu perfil, mais compatível com práticas de oralidade ou de letramento, o que se associa (embora não seja compatível nem se iguale), em certa medida, à própria caracterização do gênero textual em questão, se mais típico de situações de maior ou menor monitoração estilística.

É preciso, nesse tema, esclarecer que, embora a variação de modalidade (fala escrita) e a de registro (mais ou menos formal) não tenham equivalência no plano teórico e qualquer texto falado ou escrito possa ser mais ou menos formal, há espaços de interseção na própria configuração da norma culta escrita: os usos tidos como mais formais também costumam ser os mais esperados para as situações "mais letradas" ou "menos orais". Por esse motivo, interessa à escola conhecer a distribuição das variantes em função dos referidos contínuos.

Buscando colaborar com esse interesse, o presente artigo, na próxima seção, sistematiza o conhecimento que se tem, a partir de três descrições científicas (PEREIRA,

\footnotetext{
${ }^{5}$ Bortoni-Ricardo (2005) propõe três contínuos para a descrição da complexidade das normas de uso brasileiras: contínuo de ruralidade-urbanização, de oralidade-letramento e de monitoração estilística.
} 
2014; FERREIRA, 2013; SANTOS, 2015), acerca das estratégias de relativização na fala ou na escrita, para, ao fim, fazer reflexões adicionais sobre o tratamento da variação no Ensino de Língua Portuguesa.

\section{As estratégias de relativização no contínuo fala-escrita}

Esta seção tem como foco principal observar o comportamento das orações relativas não canônicas do caso oblíquo, aquelas que são precedidas por preposição na forma padrão, como, por exemplo, em “Esse é o livro de que você gosta”. Como já se esclareceu, trata-se de estruturas que admitem mais duas possibilidades de realização, como em "Esse é o livro que você gosta" (cortadora) e "Esse é o livro que você gosta dele" (copiadora).

Embora o tema da relativização seja muito produtivo nas pesquisas linguísticas (MOLLICA, 1977; TARALLO, 1983; CORRÊA, 2001; ABREU, 2013, dentre outros), não se dispõe de grande número de descrições sociolinguísticas acerca desse fenômeno, sobretudo considerando uma variedade de gêneros da fala e da escrita no Português do Brasil (PB). Neste artigo, resultados de três estudos variacionistas das estratégias de relativização fundamentam a descrição feita. Pereira (2014) observa o fenômeno na fala do Rio de Janeiro com base em entrevistas sociolinguísticas; Ferreira (2013) trata das estratégias de relativização em redações produzidas por estudantes em concursos de acesso à graduação na Universidade Federal do Rio de Janeiro, as chamadas redações de vestibular; e Santos (2015) investiga o fenômeno na escrita jornalística, considerando diversos gêneros textuais do Jornal O Globo, endereçado às classes alta ou média-alta. Com base em tais resultados, espera-se oferecer um panorama, ainda que limitado, de três pontos do contínuo oralidade-letramento, uma instância de fala que se pode considerar semimonitorada, uma escrita de aprendizes em contexto de avaliação, portanto monitorado; e uma escrita publicada em jornais, representativa da situação de letramento e maior formalidade. 


\subsection{As estratégias de relativização na fala do Rio de Janeiro}

Pereira (2014) observa a presença das estratégias de relativização na fala culta e popular do Rio de Janeiro, com base em ocorrências extraídas do Banco de dados Concordância ${ }^{6}$. Fundamentada em pressupostos da Teoria de Variação e Mudança (WEINREICH; LABOV; HERZOG, 1968), estabelece os fatores linguísticos e extralinguísticos que constituam os fatores condicionantes das variantes em estudo. Dois questionamentos principais norteiam a pesquisa: (1) Qual seria o perfil da fala fluminense quanto às estratégias de relativização?; (2) Qual seria a extensão da variação entre relativas cortadora e copiadora na fala fluminense em termos linguísticos e extralinguísticos?

Para responder às questões propostas, foram coletados os dados produzidos por 36 informantes de perfil urbano (18 de Copacabana/cidade do Rio de Janeiro e 18 de Nova Iguaçu, município da área metropolitana do Rio de Janeiro), entre eles homens e mulheres, com níveis de escolaridade distribuídos em Fundamental ( $6^{\circ}$ ao $9^{\circ}$ ano), Médio ( $10^{\circ}$ ao $12^{\circ}$ ano) e Superior, e faixa etária entre A (18 a 35 anos), B (36 a 55 anos) e C (56 a 75 anos). Todos os dados coletados foram codificados e submetidos ao programa computacional para análise estatística de regras variáveis, o Goldvarb- $X^{7}$, de modo a aferir o possível condicionamento dos seguintes grupos de fatores: natureza semântica do referente, função sintática do pronome relativo, distância entre o pronome relativo e o referente, e tipo de preposição (em ou de), todas linguísticas, e, ainda, região, idade, sexo e escolaridade dos informantes, estas de perfil extralinguístico.

A análise forneceu um total de 134 dados, da seguinte forma:

\footnotetext{
${ }^{6}$ Para maiores detalhes, consultar <https://concordancia.letras.ufrj.br/>.

7 Como a autora não encontrou uma regra efetivamente variável, apresenta-se apenas a distribuição dos dados em valores absolutos e percentuais.
} 
Tabela 1 - Estratégias de relativização em entrevistas sociolinguísticas no Rio de Janeiro

\begin{tabular}{|l|l|}
\hline $\begin{array}{l}\text { Relativas } \\
\text { oblíquas }\end{array}$ & $\begin{array}{l}\text { Valores absolutos } \\
\text { e percentuais }\end{array}$ \\
\hline Padrão & $7-5,2 \%$ \\
\hline Cortadora & $127-94,8 \%$ \\
\hline Copiadora & $0-0 \%$ \\
\hline Total & 134 \\
\hline
\end{tabular}

Fonte: Pereira (2014)
Gráfico 1 - Representação das estratégias de relativização em entrevistas sociolinguísticas no Rio de Janeiro

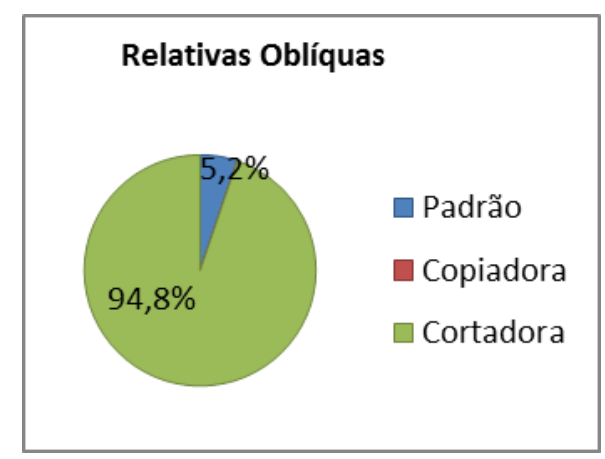

Como se pode observar, ocorreram 127 (94,8\%) casos de relativas cortadoras e apenas 07 (5,2\%) do tipo padrão, e não se registrou qualquer ocorrência da relativa copiadora no corpus analisado. Desse modo, trata-se de uma regra semicategórica, nos termos de Labov (2003), tendo opção preferencial pela estratégia cortadora, como ilustra o exemplo a seguir.

(1) se ela tivesse sido medicada de repente até com um cardiologista e visse a situação que ela estava de repente ela não teria falecido $(\mathrm{NIGB2M})^{8}$

(2) no dia que eu me formei veio um namorado que eu tinha português que eu tinha dito que só ia resolver a minha vida quando eu me formasse... (COPC3M)

Do conjunto das relativas cortadoras, vale salientar que se verificou um expressivo número de construções de natureza temporal, como hora que/ tempo que/ dia que/ época que, dentre outras, que configurariam, a nosso ver, uma espécie de processo de cristalização de locuções conjuntivas. Essas construções merecem, sem dúvida, uma investigação particular no âmbito da gramaticalização. De todo modo, foi possível atestar que a função adverbial favorece, ao que tudo indica, a estratégia cortadora.

\footnotetext{
${ }^{8}$ Os exemplos do Banco de dados Concordância (https:/concordância.letras.ufrj.br) são identificados pelo ponto de inquérito (NIG - Nova Iguaçu; COP = Copacabana), faixa etária ( $A=18$ a 35 anos; $B=36$ a 55 anos; e $\mathrm{C}$ = acima de 55 anos), escolaridade ( 1 = nível fundamental; 2 = nível médio; 3 = nível superior), sexo ( $\mathrm{H}=$ homem; $\mathrm{F}=$ mulher $)$.
} 
As únicas sete ocorrências de relativas do tipo padrão encontradas no corpus estão reproduzidas aqui para observação:

(3) a política aqui... eu não vejo assim um candidato em que eu possa confiar... não tem um candidato a prefeito que eu possa dizer assim... "ah... esse eu votaria"... mas tem que votar... né? ... a gente é obrigado (NIGA3H)

(4) tanta coisa que você fica perdido... você não sabe exatamente no que que você vai se especializar... aonde/ pra onde você vai focar sabe os seus objetivos... (COPA2M)

(5) você ficar muito tempo... ahn numa situação em que você precise pensar ponderar e falar depois de um certo tempo você se habitua a fazer isso pensando e refletindo pouco (COPB3M)

(6) você vai pro Centro vem pegar um ônibus que desça pro Rio... ou... ou tem que ir lá pra Plínio Casado em que eu já passei por dificuldades do meu tempo (...)... (NIGC2M)

(7) aqui graças a Deus eu tenho/ não tenho do que me queixar tenho muitos amigos né... $(\mathrm{COPC} 1 \mathrm{H})$

(8) na comunidade todo mundo gosta de mim... eu não tenho nada do que reclamar os vizinho tudo aqui também gosta de mim da minha esposa... (COPC1H)

(9) graças a Deus não tenho do que me queixar não já:... os moradores daqui são muito amigos... $\left(\mathrm{COP} \mathrm{C}_{1} \mathrm{H}\right)$

Observando as ocorrências, chama a atenção o fato de que quase metade delas constituam estruturas, de certa forma, cristalizadas, expressões como ter do que/ nada do que + infinitivo. Ao que tudo indica, além da limitação quantitativa, a natureza qualitativa dos dados também é muito restrita; tirando essas expressões, restam apenas quatro ocorrências e todas com a preposição em, em sua maioria introdutoras de complementos relativos/oblíquos. Do ponto de vista extralinguístico, é possível perceber, ainda, que 04, dos 07 dados, foram produzidos por falantes idosos (faixa C). Esse resultado também pode sinalizar um possível desuso crescente da relativa padrão. 
Em síntese, considerando a análise geral dos dados, constata-se que a regra em questão é de natureza semicategórica (LABOV, 2003). Com relação às variantes não padrão (cortadora e copiadora), elas não competem na fala observada no Rio de Janeiro, uma vez que só a variante cortadora é encontrada no corpus, mostrando uma forte tendência brasileira. Ao que tudo indica, esse tipo de estrutura "é de uso generalizado no PB" (CORRÊA, 2001, p. 625) e funciona como uma estratégia de esquiva, pois é uma forma não marcada e que não tem um perfil estigmatizante, como o da copiadora.

O fato de não se ter encontrado qualquer ocorrência da estratégia copiadora também merece reflexão adicional. Tendo em vista que a produção e a interpretação da estratégia copiadora fazem parte da variedade brasileira, cabe a indagação: em que contextos estruturais e sociais essa estratégia apareceria? Por hipótese, supõe-se que ela estaria relacionada a funções discursivas particulares. Ao que tudo indica, a retomada do pronome átono em estratégias copiadoras relaciona-se a contextos em que se deseja destacar um referente, como é o caso da topicalização (por ex., o rapaz, aquele que eu encontrei ele ontem, saiu), por exemplo. Associada a essas funções, é provável que razões estruturais, como a tendência ao preenchimento do sujeito, também sejam observadas, visto que, mesmo nessa posição sintática, pode ser encontrado o pronome-cópia (por ex., o rapaz, que ele estava lá em casa ontem, saiu). Em um ou outro contexto, a repetição do referente pelo pronome-cópia garantiria o destaque que se deseja dar a seu conteúdo. Obviamente, as hipóteses aqui aventadas dependem de investigação em materiais, provavelmente produções faladas com alto grau de espontaneidade, em que as estratégias copiadoras venham a ser registradas.

Por outro lado, as relativas padrão encontradas no corpus são quantitativa e qualitativamente muito restritas. Estruturalmente, ocorrem com poucas formas verbais que selecionam complementos relativos e, ainda, contêm algumas expressões cristalizadas, como ter do que/ nada do que, como já dito anteriormente. Em termos extralinguísticos, no que se refere à idade dos falantes, ocorrem, em sua maioria, na fala da faixa $C$, o que pode sugerir o crescente desuso dessa variante no eixo temporal. 


\subsection{As estratégias de relativização em gêneros escritos}

Ferreira (2013) investiga o comportamento das estratégias de relativização na escrita de redações submetidas ao concurso de acesso à graduação da Universidade Federal do Rio de Janeiro, para o ano de 2009. Trata-se, portanto, de textos dissertativoargumentativos com considerável grau de monitoração, visto que o chamado “atendimento ao padrão culto da língua portuguesa" constitui um dos quesitos da grade de avaliação do processo seletivo. O autor objetiva analisar, em uma perspectiva variacionista, além da distribuição geral dos dados pelas estratégias em questão, os contextos linguísticos em que ocorre cada uma das formas alternantes. Ademais, o estudo verifica a relação existente entre a frequência de relativas não padrão [- padrão] e a nota atribuída aos textos quanto ao "atendimento ao padrão culto".

O corpus considerado na pesquisa é composto por 140 redações do referido processo seletivo, redações que integram o Corpus "Rio Acadêmico-Escolar" ", sendo 35 textos de cada uma das quatro atribuições de notas no quesito chamado atendimento ao padrão culto da língua, a saber: 0,5 (meio); 1,0 (um); 1,5 (um e meio) e 2,0 (dois).

Considerando a metodologia de análise sociolinguística variacionista, Ferreira (2013) coletou, inicialmente, todas as orações relativas preposicionáveis (oblíquas) encontradas no total de 140 textos analisados ${ }^{10}$. Codificadas as ocorrências e submetidas ao tratamento provido pelo Programa Goldvarb- $X^{11}$, o autor investiga, além da correlação entre a nota recebida pela redação e o tipo de estratégia de relativização empregado, o possível condicionamento dos seguintes grupos de fatores linguísticos: tipo de pronome relativo, natureza semântica do referente, função sintática do pronome, distância entre o pronome relativo e o referente e tipo de preposição (em ou de).

A análise forneceu um total de 84 orações adjetivas, distribuídas da seguinte forma:

\footnotetext{
${ }^{9}$ Esse conjunto de textos de natureza acadêmica e escolar foi organizado por Silvia Rodrigues Vieira e Adriana Lopes Rodrigues Coelho.

${ }^{10}$ De modo a garantir a comparabilidade dos resultados, não foram computadas em conjunto orações que apresentassem dequeísmo ou preposições distintas das esperadas na norma-padrão, igualmente desconsideradas neste artigo.

${ }^{11}$ Devido ao pequeno número de dados, o autor vale-se exclusivamente de índices percentuais.
} 
Tabela 2 - Estratégias de relativização em redações de vestibular no Rio de Janeiro

\begin{tabular}{|l|l|}
\hline $\begin{array}{l}\text { Relativas } \\
\text { oblíquas }\end{array}$ & $\begin{array}{l}\text { Valores absolutos } \\
\text { e percentuais }\end{array}$ \\
\hline Padrão & $59-70 \%$ \\
\hline Cortadora & $25-30 \%$ \\
\hline Copiadora & $0-0 \%$ \\
\hline Total & 84 \\
\hline
\end{tabular}

Fonte: Ferreira (2013)
Gráfico 2 - Representação das estratégias de relativização em redações de vestibular no Rio de Janeiro

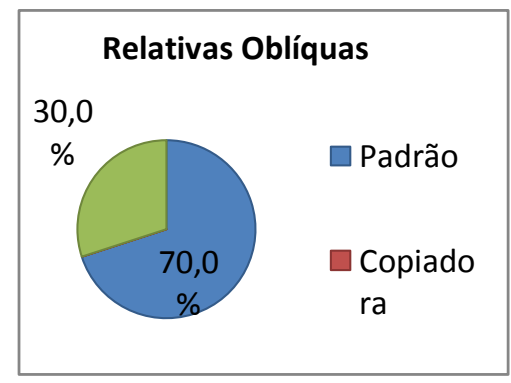

Considerando o número de dados registrados, Ferreira (2013) verificou a preferência dos estudantes nas redações de concursos pela relativa padrão (70\%), embora também tenham utilizado a variante cortadora (30\%). Quanto às copiadoras que, ao que tudo indica, são produzidas em contextos mais específicos, mesmo na fala -, também não foram encontrados exemplos nas redações escolares.

Sendo a variante cortadora a forma preferencial na fala, pode-se observar que a escolarização média não atua no sentido de eliminar essa variante na escrita culta formal produzida pelos alunos, embora colabore fortemente para a sua substituição em favorecimento à estratégia padrão. A seguir, alguns dados da variante não padrão:

(10) Cabe a cada um pensa, se a razão é se deixar levar pela emoção de fazer aquilo que gosta.

(11) Vivemos em um mundo que a mídia colocou conceitos para as pessoas julgarem, quem é o serto e o errado...

Embora o uso da estratégia padrão tenha sido considerável, é relevante observar o perfil dessas orações, que não é muito diversificado nem complexo. No que se refere ao pronome relativo em questão ${ }^{12}$, as orações relativas são basicamente construídas com a

\footnotetext{
${ }^{12}$ Ferreira (2013) não computou os dados da forma onde e suas variantes, devido à especificidade desse contexto, que mereceria investigação particularizada.
} 
forma que e o contexto de uso mais frequente é aquele em que esse pronome cumpre o papel de complemento oblíquo ou adjunto adverbial. Observam-se, a seguir, alguns exemplos:

(12) No mundo em que vivemos acontecem muitas loucuras por falta de recursos e de uma boa educação.

(13) Muitos dos grandes cientistas e inventores, hoje reconhecidos, já foram considerados loucos na época em que viveram.

No que se refere ao perfil dos estudantes que utilizaram as estratégias padrão, Ferreira (2013) investigou a correlação entre o uso dessas formas alternantes e a nota recebida no quesito identificado como atendimento ao padrão culto. Os resultados dessa investigação encontram-se na tabela a seguir:

Tabela 3- Estratégias de relativização em redações de vestibular no Rio de Janeiro segundo a nota recebida no quesito "atendimento a padrão culto"

\begin{tabular}{|c|c|c|}
\hline $\begin{array}{ll}\text { Nota } & \text { recebida } \\
\text { em } & \text { "padrão } \\
\text { culto" } & \end{array}$ & Cortadora & Padrão \\
\hline 0,5 & $14 / 25-56 \%$ & $11 / 25-44 \%$ \\
\hline 1,0 & $3 / 17-17,6 \%$ & $14 / 17-82,4 \%$ \\
\hline 1,5 & $3 / 17-17,6 \%$ & $14 / 17-82,4 \%$ \\
\hline 2,0 & $5 / 25-20 \%$ & $20 / 25-80 \%$ \\
\hline
\end{tabular}

Fonte: Ferreira (2013)

De fato, a relativa não padrão ocorre em redações que receberam qualquer das notas atribuídas. Verificou-se, entretanto, maior produtividade dessa variante nas redações que receberam a nota mais baixa no quesito referente ao atendimento a padrão culto - 0,5 (meio) -, contrastando com os índices relativos às redações a que foram atribuídas as demais notas. Embora o fenômeno linguístico em análise possa não ser muito saliente para ser percebido em avaliações em massa - como seria, por exemplo, a 
ausência de concordância verbal padrão ${ }^{13}$-, fica evidente que a falta de domínio das estruturas consideradas cultas também o abrange.

Para interpretar o estatuto social das estratégias de relativização, é, ainda, relevante verificar o emprego dessas variantes em meios considerados manifestações de expressões cultas e formais, como na escrita acadêmica e jornalística. Nesse sentido, Santos (2015) oferece um panorama dos usos em jornal de grande circulação no Rio de Janeiro, contemplando diversos gêneros textuais. Fundamentado nos pressupostos da Sociolinguística Variacionista, o trabalho foi desenvolvido a partir de três etapas: (i) a descrição do uso das estratégias de relativização; (ii) a comparação dos resultados obtidos com os verificados na fala brasileira; e (iii) a análise da Coluna Autocrítica, do Jornal O Globo, em que se exibem os comentários dos revisores linguísticos. Para a primeira dessas etapas, que interessa de modo especial ao presente artigo, a pesquisa conta com um corpus composto por 150 textos publicados no Jornal O Globo durante o período de janeiro a outubro de 2012, que incluem os seguintes gêneros do domínio jornalístico: editoriais, artigos de opinião, crônicas, notícias, cartas de leitor e anúncios.

A coleta dos dados para o tratamento quantitativo resultou em um total de 253 ocorrências, incluindo as orações não preposicionadas (aquelas em que o pronome relativo exerce os papéis de sujeito, objeto direto ou predicativo do sujeito) - todas realizadas pela variante padrão, não tendo ocorrido qualquer caso de cortadora - e outro com as orações preposicionadas, que se distribuíram conforme os índices da tabela a seguir.

\footnotetext{
${ }^{13}$ A esse respeito, consultar o trabalho de Vieira; Pires (2012), que, valendo-se do mesmo corpus, atestam o decréscimo das marcas de plural em paralelo à diminuição das notas na avaliação do atendimento ao padrão culto.
} 
Tabela 4 - Estratégias de relativização em textos de Jornal O Globo no Rio de Janeiro

\begin{tabular}{|l|l|}
\hline $\begin{array}{l}\text { Relativas } \\
\text { oblíquas }\end{array}$ & $\begin{array}{l}\text { Valores absolutos } \\
\text { e percentuais }\end{array}$ \\
\hline Padrão & $97-95,1 \%$ \\
\hline Cortadora & $5-4,9 \%$ \\
\hline Copiadora & $0-0 \%$ \\
\hline Total & 102 \\
\hline
\end{tabular}

Fonte: Santos (2015, p. 85)
Gráfico 3 - Representação das estratégias de relativização em textos do Jornal O Globo no Rio de Janeiro

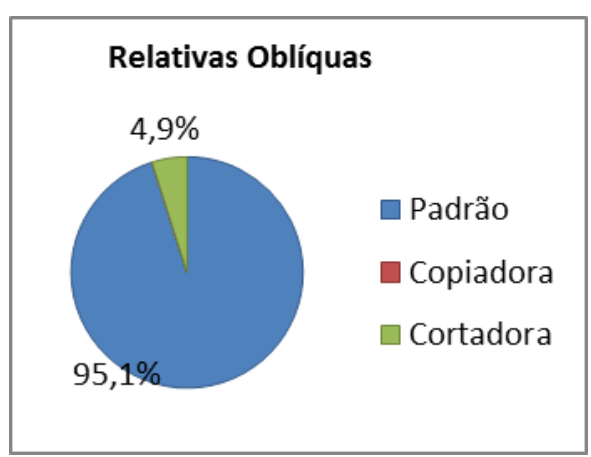

Como se pode observar, os resultados relativos à escrita culta brasileira são inversamente proporcionais aos encontrados por Pereira (2014) na fala do Rio de Janeiro. Os dados dos textos jornalísticos apresentaram o uso semicategórico da variante padrão (95,1\%), contrapondo-se a apenas poucas ocorrências da variante cortadora (4,9\%). A relativa copiadora, como era de se esperar, dado seu valor estigmatizante e seu uso específico em termos discursivos, não foi registrada no corpus jornalístico.

Diferentemente dos usos detectados na escrita de estudantes, há certa variedade estrutural das orações padrão observadas nas publicações em jornais, como revelam os dados a seguir:

(14) Além disso, vive-se num mundo digitalizado em que há enorme e crescente capacidade de armazenamento de informações sobre o cidadão por parte do Estado. A integração desses bancos de dados, aos quais poucos servidores públicos têm acesso, é algo preocupante do ponto de vista dos riscos à privacidade. (O GLOBO, 28/09/12, EDITORIAL: A quebra de sigilo pela Receita, Caderno Geral, p. 22)

(15) O problema é que a mudança reintroduz, pela porta dos fundos, a famigerada tributação cumulativa sobre faturamento, uma deformidade fiscal desnecessária 
da qual o país havia praticamente se livrado, graças ao louvável esforço de reforma tributária do primeiro governo do presidente Lula. (O GLOBO, 28/og/12, ARTIGO DE OPINIÃO: Improvisação e imediatismo, Caderno Geral, p. 22)

(16) Decido apropriar-me da zona franca da Divina Comédia e imagino traduzir a cena política do Brasil, segundo as lentes de um Dante redivivo, mantendo a vigilância ética, incômoda, inarredável, com que definiu os crimes deste mundo e as penas do outro. (O GLOBO, 19/09/12, CRÔNICA: Dante e a Justiça, Caderno Geral, p. 23)

(17) Eu era imensamente rico, morava num castelo, mas dava poucos presentes. Mas eu lembro - disse o velho do tersol - do seu desespero no avião cujo trem de aterragem não descia. (O GLOBO, 19/09/12, CRÔNICA: conversa de velhos, Caderno Geral, p. 23)

Os exemplos demonstram que se trata de orações com variadas formas de pronomes relativos - que, o qual, cujo, onde -, combinadas com diversas preposições, quando estas se aplicam, quais sejam: em (a mais produtiva), com, a, de, por, para, dentre outras. Desse modo, são igualmente variadas as relações gramaticais estabelecidas entre participantes das orações encaixadas e os pronomes relativos, cuja função pode ser de complementos ou adjuntos de verbos ou, ainda, complementos ou adjuntos de nomes.

Os dados de estratégias cortadoras encontrados no trabalho de Santos (2015), além de serem em quantidade reduzida, são, ao contrário das relativas padrão, bastante específicos. A seguir, os únicos exemplos encontrados pela autora.

(18) Liberty torpedo: a tarifa de R\$ 12,90 será cobrada somente no mês que houver utilização e é valida para enviar torpedos [sms] ilimitados, dentro da rede TIM, para qualquer operadora do Brasil no mês que usar. (O GLOBO, 03/10/12, ANÚNCIO: propaganda da TIM, Caderno Geral p. 06)

(19) (...) Liberty web smart: a tarifa de $R \$ 29,90$ será cobrada somente no mês que houver utilização de dados/internet. (...) (O GLOBO, 03/10/12, ANÚNCIO: propaganda da TIM, Caderno Geral p. 06) 
(20) (...) Liberty torpedo: a tarifa de $\mathrm{R} \$ 12,90$ será cobrada somente no mês que houver utilização e é valida para enviar torpedos [sms] ilimitados, dentro da rede TIM, para qualquer operadora do Brasil no mês que usar. (O GLOBO, 03/10/12, ANÚNCIO: propaganda da TIM, Caderno Geral p. 06)

(21) Pense em um dia que você não precise pegar no carro. De cara, você já economizou o dinheiro da gasolina, o tempo que estaria procurando vaga e o stress de dirigir no trânsito, que estaria bem mais tranquilo se a maioria pensasse igual e também não pegasse no carro. ( $O$ GLOBO, 19/09/12, ANÚNCIO DA FETRANSPOR, Caderno Geral, p. 20)

(22) Pense em um dia que você não precise pegar no carro. De cara, você já economizou o dinheiro da gasolina, o tempo que estaria procurando vaga e o stress de dirigir no trânsito, que estaria bem mais tranquilo se a maioria pensasse igual e também não pegasse no carro. (O GLOBO, 19/09/12, ANÚNCIO DA FETRANSPOR, Caderno Geral, p. 20)

Como se pode verificar, as cinco ocorrências de relativas cortadoras nos jornais contam com o pronome relativo "que" exercendo o papel de adjunto adverbial de tempo, em construções que supostamente contariam com a preposição “em”.

Além da simplicidade estrutural dessas ocorrências, chama a atenção uma característica relacionada ao gênero textual em que elas apareceram: todas foram produzidas em anúncios publicitários (5/14 - 35,7\%). Constata-se, então, que mesmo esse contexto estrutural típico de estratégias cortadoras, já comentado anteriormente quanto à possibilidade de ser visto como uma expressão temporal integrada, não parece ter entrada livre no suporte jornalístico. Na realidade, ao que tudo indica, a avaliação negativa ${ }^{14}$ da variante cortadora, em oposição ao prestígio da variante padrão, implica seu aparecimento apenas em gêneros que não são efetivamente do domínio jornalístico,

\footnotetext{
${ }^{14}$ Embora não caiba nos propósitos deste artigo nem no espaço de que se dispõe, é importante destacar que Santos (2015) procedeu à análise das correções indicadas pelos revisores do Jornal na Seção Autocrítica, que contém a indicação dos problemas linguísticos da edição anterior. Nessa análise, a autora propõe que as variantes não padrão, cortadora e copiadora, constituem estereótipos negativos para o revisor/jornalista.
} 
mas publicitário. Os anúncios têm por característica maior liberdade estilística, o que, em alguma medida, pode justificar o uso de uma estratégia não padrão.

\section{As estratégias de relativização, o contínuo fala-escrita e o ensino de Português}

Com base na síntese dos resultados gerais dos estudos variacionistas em questão e, ainda, nos pressupostos adotados para o ensino de Língua Portuguesa, é possível propor algumas reflexões relativas ao tratamento das estratégias de relativização - e, por extensão, de outros fenômenos variáveis - no continuum fala-escrita.

Primeiramente, chama atenção o fato de não se ter registrado qualquer ocorrência da variante copiadora, o que sinaliza, como já se observou, a especificidade dessa forma alternante. Por hipótese, supõe-se que ela se correlacione a efeitos discursivos de topicalização e ênfase, por exemplo, e que provavelmente ocorra em gêneros de concepção falada de alto grau de espontaneidade. Sem dúvida, esses contextos devem ser trabalhados nas aulas de Língua Portuguesa.

Quanto à produtividade das demais variantes, verifica-se a diferença de comportamento a depender dos gêneros textuais controlados nos estudos. Dispostos os índices percentuais gerais da variante padrão, podem-se visualizar as tendências gerais na figura a seguir.

Figura 1 - Continuum fala-escrita: produtividade das estratégias de relativização padrão

\begin{tabular}{|c|c|c|c|}
\hline $\begin{array}{c}\text { [- padrão] } \\
\text { [+cortadora] }\end{array}$ & RJ & RJ & $\begin{array}{l}\text { [+ padrão] } / \\
\text { [-cortadora }]\end{array}$ \\
\hline $\begin{array}{c}\text { RJ } \\
\text { Fala urbana } \\
\text { Entrevistas } \\
\text { sociolinguísticas }\end{array}$ & $\begin{array}{c}\text { Escrita escolar } \\
\text { Redações de } \\
\text { vestibular }\end{array}$ & $\begin{array}{c}\text { Escrita em jornais } \\
\text { Anúncios }\end{array}$ & $\begin{array}{c}\text { Escrita em jornais } \\
\text { Editoriais, notícias, } \\
\text { crônicas }\end{array}$ \\
\hline $5.2 \%$ & $30 \%$ & $64.3 \%$ & $100 \%$ \\
\hline
\end{tabular}


Embora seja necessário relativizar a generalidade dos resultados, dado o baixo número de dados encontrados em certos materiais, pode-se afirmar que o comportamento das estratégias de relativização é sensível ao perfil dos gêneros textuais em questão, não só quanto à modalidade (se falada ou escrita), mas também quanto ao suposto maior ou menor grau de controle das opções linguísticas. De fato, a variante padrão é bem produtiva em níveis elevados de letramento, o que não se verifica quando o contexto de produção é prototípico da fala. Ao contrário, a produtividade da variante não padrão cortadora é elevada na extremidade da oralidade e diminui ou até é extinta quanto mais a produção se aproxima do extremo do letramento.

O comportamento inverso nas extremidades do contínuo permite afirmar que a variabilidade dos usos cultos é absoluta - vai de 5 a 100\% a expressão da estratégiapadrão. Se levarmos em consideração que os indivíduos que representam a fala urbana incluem falantes com curso superior, tendo, portanto, o mesmo perfil sociolinguístico dos que escrevem nos jornais, a primeira importante contribuição para o contexto pedagógico é a validação empírica de que não existe a "norma culta”, como uma variedade de contornos homogêneos, mas usos cultos variáveis em função dos contínuos oralidade-letramento e monitoração estilística. Sendo assim, qualquer orientação do tipo “pra que ensinar relativa padrão, já que não constitui uma variante brasileira?" seria no mínimo ingênua, visto que desprezaria a norma culta efetivamente praticada na mídia brasileira e impediria a escola de desenvolver as instâncias de letramento que dela se espera. Da mesma forma, qualquer orientação pedagógica que ignore a opção preferencial pela relativa cortadora seria improdutiva, visto que, sendo esta representativa das falas cultas e populares, figura em vários gêneros de concepção oral da fala espontânea aos anúncios publicitários, por exemplo. Ademais, é preciso salientar que o desprezo à variante cortadora impediria o trabalho de reflexão linguística - com base em atividades linguísticas, epilinguísticas e metalinguísticas (FRANCHI, 2006) necessário para que os estudantes tenham, ao menos, compreensão da variante padrão.

Assim sendo, ainda que fique evidente o comportamento inverso se forem considerados os extremos do continuum (sobretudo se imaginarmos uma fala totalmente espontânea, em que pode até mesmo não aparecer a estratégia padrão), não convém ao 
professor de Português adotar uma visão dicotômica que gere uma orientação do tipo “na escrita, usa-se a variante padrão e na fala usa-se a variante não padrão". No que se refere aos textos divulgados em jornais, a particularidade do comportamento dos anúncios frente aos demais gêneros, por exemplo, permite supor que grande variabilidade no emprego das estratégias de relativização deve ser encontrada se levarmos em conta a pluralidade de gêneros de domínios discursivos diversos. A escrita dos indivíduos em redações de vestibular demonstra, ainda, que a variante padrão constitui uma estratégia perseguida por muitos, mas que seu emprego depende do domínio das estruturas propostas na chamada norma-padrão (e que se efetivam em circunstâncias particulares da escrita culta) de modo a se concretizar na produção de indivíduos em processo de letramento.

De todo modo, chama atenção o índice categórico da estratégia padrão em textos efetivamente jornalísticos, o que sugere ser essa variante um forte marcador de letramento, cujo emprego depende do exercício consciente do indivíduo que o produza. É nesse sentido que se pode aventar a hipótese de que estaria atuando, de forma associada à modalidade (fala-escrita), o grau de monitoração estilística (formal-informal). Levando em conta a possível superposição do grau de monitoração e da modalidade nos extremos do continuum, verifica-se que o nível de controle das variantes é elevado na escrita jornalística e é de mediano a baixo na fala estudada, por se tratar de entrevistas sociolinguísticas (contexto semiespontâneo), de modo que, ao menos superficialmente, alta monitoração se combinaria com maior uso de estratégias padrão e baixa monitoração levaria ao menor uso dessas construções. Entretanto, não se pode verificar essa correlação no caso das redações de vestibular, por exemplo, em que inegavelmente os indivíduos que as produzem se encontram em situação discursiva de inegável alta monitoração, dada a avaliação do quesito "atendimento a padrão culto", mas não fazem o mesmo uso das estratégias de relativização.

Ao que tudo indica, a complexidade de influências quanto aos índices adotados em cada perfil do gênero textual correlaciona-se às exigências de adesão aos modelos da norma-padrão e, consequentemente, ao domínio desses modelos. Em outras palavras, o indivíduo só fará uso da estratégia padrão, primeiramente, se for altamente escolarizado 
e tiver aprendido (ou "adquirido"") essas estruturas, muitas vezes como outra norma/variedade (ou, segundo concepções gerativistas, outra "gramática”) que vai usar quando esse emprego Ihe for exigido. É nesse sentido que se justifica a diferença de comportamento entre os estudantes que tiveram o mais baixo desempenho nas redações de vestibular (com menor índice de realização de estratégias padrão) e os demais indivíduos. Por mais que estivessem em situação de alta monitoração estilística, boa parte desses estudantes não dispunha desse recurso para empregar nas redações.

Desse modo, adquirida a condição para usar a estratégia padrão - tê-la adquirido/aprendido, já que ela não pertenceria ao vernáculo brasileiro -, o usuário da língua evitará o uso da estratégia cortadora se estiver em:

(i) evento concebido como típico de alto letramento (e não de oralidade) - o que justificaria a diferença entre conversas informais faladas, anúncios, conversas de Whatsapp, concebidas como [+ orais], por exemplo, e gêneros jornalísticos, como notícias e editoriais, ou acadêmicos, como artigos científicos, concebidos como [+ escritos]; e

(ii)contexto de alta monitoração estilística - o que justificaria a diferença entre conversas de familiares, e-mails pessoais, concebidos como [- formais/monitoradas] e redações escolares ou notícias jornalísticas, concebidas como [+ formais/+ monitoradas].

Nesse sentido, é possível fazer certa correlação entre uso da variante padrão e eventos de letramento e grau de monitoração estilística, correlação que se daria de forma escalar e estaria no plano da consciência do indivíduo que emprega essas estratégias. Tudo isso, é preciso lembrar, ainda se relacionaria a empregos com produtividades distintas no que se refere aos condicionamentos linguísticos, a depender do tipo de pronome relativo e da estrutura morfossintática em questão. Em outras palavras, a variante em questão não se comporta, em termos labovianos (LABOV, 1972), como

\footnotetext{
${ }^{15}$ Embora não caiba nos limites deste artigo, a adoção da estratégia padrão por parte dos usuários da língua pode ser interpretada, considerando pressupostos teóricos formalistas, como a aquisição de outra "gramática", visto que tal estrutura não pertenceria à fase primeira de aquisição da língua pelas crianças. Em termos labovianos, admite-se que se trata de aprendizagem de variante de outra norma, diferente do que se pratica em conversas espontâneas ou no que se chama norma vernacular.
} 
indicador (forma alternante que não é percebida pelos falantes), mas como marcador ou, até mesmo, uma espécie de "estereótipo positivo", que indicaria, no plano da consciência, indivíduos de alto grau de letramento.

\section{Considerações finais}

Evidências empíricas não faltam para que se instaure, de forma mais do que urgente, uma consciência pedagógica que assuma o óbvio postulado de que a norma culta, tomada como conjunto de variedades, é variável. Desse modo, qualquer orientação normativa que negue esse postulado se presta à promoção de práticas artificiais de treino linguístico ou, no mínimo, à promoção de discriminação social de usos variáveis.

O comportamento das estratégias de relativização constitui forte evidência de que não se pode negar a valoração social das variantes, em função do contínuo fala-escrita e, em certos contextos, dos graus de monitoração estilística, tudo isso permitido pelo domínio de recursos nada familiares ao vernáculo brasileiro, como a estratégia relativa padrão. Entretanto, em nada a variabilidade no âmbito desse fenômeno impede reafirmar a proposta de Faraco (2015), de que se desenvolva uma pedagogia da variação linguística, que admita a pluralidade mesmo no âmbito da formulação de guias normativos.

Por fim, cabe retomar a proposta de Vieira $(2014,2017)$ e relacionar o chamado ensino de normas à conjugação de três eixos para o ensino de fenômenos gramaticais (Eixo 1. abordagem reflexiva do componente linguístico; Eixo 2. gramática como produção de sentidos; e Eixo 3. análise de regras variáveis). O trabalho com as estratégias de relativização (Eixo 3) reafirma a necessidade de que se alie, também, o tratamento do fenômeno à produção e à interpretação de textos nos seus variados gêneros (Eixo 2), sem deixar de abordar os conteúdos gramaticais segundo uma abordagem reflexiva (Eixo 1). Não será possível um trabalho efetivo com esse fenômeno gramatical sem atividades que promovam o reconhecimento efetivo das funções sintáticas exercidas pelas orações adjetivas, como um todo, e pelos pronomes relativos, em particular.

Esperamos, assim, ter contribuído com o conhecimento da pluralidade de normas linguísticas com que a escola convive, no plano da realização ou da idealização, e ter 
colaborado para o trabalho produtivo com o componente linguístico em salas de aula de Língua Portuguesa. Desse modo, possa o professor, fundamentado em resultados científicos, desenvolver estratégias para cumprir o propósito de promover a ampliação do repertório linguístico dos alunos, de modo que usem e reconheçam formas alternantes diversificadas em gêneros textuais igualmente variados, sem com isso desmerecer a riqueza e a complexidade das normas em convívio.

\section{Referências}

ABREU, Ana Cristina Baptista de. Aquisição de orações relativas no português brasileiro. 2013. Dissertação (Mestrado em Linguística) - UFRJ, Faculdade de Letras, Rio de Janeiro, 2013.

BORTONI-RICARDO, Stella Maris. Um modelo para a análise sociolingüística do português brasileiro. In: BORTONI-RICARDO, Stella Maris. Nós cheguemu na escola, e agora? sociolinguística e educação. São Paulo: Parábola Editorial, 2005, p. 45-52.

BRASIL. Ministério da Educação. Parâmetros Curriculares Nacionais: língua portuguesa. Brasília: MEC, 1998. Disponível em: <http://portal.mec.gov.br/seb/arquivos/pdf/ portugues.pdf>. Acesso em: 10 ago. 2017.

CORRÊA, Vilma Reche. Variação sintática em Portugal e no Brasil: orações relativas. In: ENCONTRO NACIONAL DA ASSOCIAÇÃO PORTUGUESA DE LINGUÍSTICA, XVI, Lisboa 2001. Actas... Lisboa: APL, 2001, p. 615-626.

FARACO, Carlos Alberto. Norma culta brasileira: desatando alguns nós. São Paulo: Parábola Editorial, 2008.

FARACO, Carlos Alberto. Norma culta brasileira: construção e ensino. In: ZILLES, Ana Maria Stahl; FARACO, Carlos Alberto. (Orgs.) Pedagogia da variação linguística: língua, diversidade e ensino. São Paulo: Parábola Editorial, 2015, p. 19-30.

FERREIRA, Vítor Araújo. O tratamento das orações relativas em redações de vestibular variação e correção. In: JORNADA DE INICIAÇÃO CIENTÍFICA, ARTíSTICA E CULTURAL JÚLIO MASSARANI, XXXV, Rio de Janeiro 2013. Rio de Janeiro: UFRJ, 2013.

FRANCHI, Carlos. Mas o que é mesmo “gramática”? São Paulo: Parábola Editorial, 2006. 
LABOV, William. Sociolinguistic patterns. Philadelphia: University of Pennsylvania Press. 1972.

LABOV, William. Some sociolinguistic principles. In: PAULSTON, Christina Bratt; TUCKER, G. Richard (eds.). Sociolinguistics: the essencial readings. Oxford: Blackwell, 2003, p. 235250.

MARCUSCHI, Luiz Antônio. Gêneros textuais no ensino de língua. In. MARCUSCHI, Luiz Antônio. Produção textual, análise de gêneros e compreensão. São Paulo: Parábola Editorial, 2008, p. 144-225.

MOLLICA, Maria Cecília de Magalhães. Estudo sobre a cópia nas construções relativas em português. 1977. Dissertação (Mestrado em Linguística) - PUC-RIO, Departamento de Letras, Rio de Janeiro, 1977.

PEREIRA. Talita Silva. Estratégias de relativização da fala brasileira: uma perspectiva sociolinguística. In: JORNADA DE INICIAÇÃO CIENTÍFICA, ARTÍSTICA E CULTURAL JÚLIO MASSARANI, XXXVI, Rio de Janeiro, 2014. Rio de Janeiro: UFRJ, 2014.

SANTOS, Juliana da Costa. O comportamento das estratégias de relativização na escrita culta jornalística brasileira. 2015. Dissertação (Mestrado em Letras Vernáculas) - UFRJ Faculdade de Letras, Rio de Janeiro, 2015.

TARALLO, Fernando. Relativization Strategies in Brazilian Portuguese. 1983. Ph.D. dissertation University of Pennsylvania, Pennsylvania, 1983.

VIEIRA, Silvia Rodrigues. Orientações oficiais para o ensino de gramática: uma proposta em três frentes de trabalho. In: ENCONTRO NACIONAL DAS LICENCIATURAS (ENALIC), V, Natal, 2014. Natal: UFRN, 2014.

VIEIRA, Silvia Rodrigues. Três eixos para o ensino de gramática: uma proposta experimental. In: NORONHA, Claudianny Amorim; SÁ JR., Lucrécio Araújo de. (Orgs.) Escola, ensino e linguagem [recurso eletrônico]. Natal-RN, EDUFRN, 2017. Disponível em: http://repositorio.ufrn.br. Acesso em: 25 jun. 2017.

VIEIRA, Silvia Rodrigues; FREIRE, Gilson Costa. Variação morfossintática e ensino de Português. In: MARTINS, Marco Antônio; VIEIRA, Silvia Rodrigues; TAVARES, Maria Alice. (Orgs.) Ensino de português e sociolinguística. São Paulo: Contexto, 2014, p. 81-114.

VIEIRA, Silvia Rodrigues; PIRES, Juliana Cristina de Paula. Padrões variáveis de concordância verbal em redações de vestibular: restrições e avaliação. Matraga, Rio de Janeiro: UERJ, v. 19, n.30, p. 168-188, 2012. 
WEINREICH, Uriel; LABOV, William; HERZOG, Martin. Empirical foundations for theory of linguistic change. In: LEHMANN, Winfred; MALKIEL, Yakov (Orgs.) Directions for historical linguistics. Austin: University of Texas Press, 1968, p. 97-195.

Recebido em: 04/07/2017 Aprovado em: 04/09/2017

Universidade do Estado de Santa Catarina - UDESC Centro de Ciências Humanas e da Educação - FAED

Revista PerCursos Volume 18 - Número 37 - Ano 2017 revistapercursos@gmail.com 